\title{
Applying decision trees for value-based customer relations management: Predicting airline customers' future values
}

Received (in revised form): 15th January, 2007

\section{Giuliano Tirenni}

is a Post Doc at the Center for Business Metrics at University of St. Gallen, Switzerland.

\section{Christian Kaiser}

is a Post Doc at the Center for Business Metrics at University of St. Gallen, Switzerland.

\section{Andreas Herrmann}

is a Director at the Center for Business Metrics at University of St. Gallen, Switzerland.

Keywords marketing, customer equity management, decision trees

\begin{abstract}
This paper outlines a general methodology for the segmentation of customers according to lifetime value and prediction of their future value segments based on demographic and behavioural features. Not only have few previous scientific studies dealt with this question using nonaggregate single-customer data, but also we address the problem using decision trees, which has rarely been done before. Applying our method to customer data from a major European airline produces predictions not only for longterm, middle-term, and short-term customers but also for prospects whose value is difficult to predict because of limited information. Overall, our findings provide marketing managers a means to optimise company customer equity and maximise returns on marketing in the long run.

Journal of Database Marketing \& Customer Strategy Management (2007) 14, 130-142.

doi:10.1057/palgrave.dbm.3250044
\end{abstract}

\section{INTRODUCTION}

\section{Outline}

According to the literature, investing in customer retention is often more efficient than acquiring new customers. ${ }^{1}$ Hence, a considerable amount of research has addressed factors and strategies to retain customers. several papers, however, including Anderson and Mittal, ${ }^{2}$ Niraj et al., ${ }^{3}$ and Reinartz and $\mathrm{Kumar}^{4}$ emphasise that it may not be profitable to retain every customer. Rather, the relationship between costs and value must be taken into consideration; that is, customers are not profitable if the costs generated to serve them exceed revenues in the long term. Thus, firms should consider reducing services for these customers or even terminate the relationship entirely. ${ }^{5}$

The benefits of customer segmentation for customer retention extend to customer acquisition. If the firm is aware of the profitability of new customers beforehand, it can choose its level of marketing investment according to the expected return from this customer. Yet another strategy consists of 
increasing a customer's value for the firm by converting him/her into a member of a higher profitability segment. This tactic, again, can be achieved if the main value drivers are known to the company. Thus, valuation of customers and knowledge of customer features and behaviour that allow prediction of a customer's value segment are indispensable for optimising marketing investments.

We obtain satisfying results in predicting customer value using decision trees, which have some important advantages over other methods, including high flexibility and ability to handle categorical variables. Particularly interesting for practical implementation is the identification of workable rules that allow managers to easily classify customers according to their attributes and thus implement profitmaximising marketing strategies.

The structure of the paper is as follows. Following a short conceptual overview of the measurement and prediction of customer lifetime value in earlier studies, we present an introduction to decision trees.

Next, we illustrate our approach with a case study using customer data from a major European airline. This section describes attributes of the database and presents the distribution and segmentation of customer values in our database. We then use decision trees to predict the value segment of a given customer based on observable demographic and behavioural features. Depending on the duration of the previous customer-firm relationship, different information is available to us; therefore, we obtain very different results. Most noteworthy - even for prospective customers for whom no prior behavioural data are available - we obtain very good predictions of future customer value. To the best of our knowledge, such evaluation of prospects has not yet been addressed in the customer lifetime value literature. We conclude by discussing the results and managerial implications.

\section{Concept and prediction of customer lifetime value}

To choose the appropriate investment into acquiring or retaining a customer, a first question that must be answered is how to segment customers according to their utility for the firm. As Woo and Fock ${ }^{1}$ note, 'the main differences in characterising right and wrong customers are satisfaction level and profitability'. One measure used by several researchers in recent years to express longrun customer profitability is lifetime value, for whose computation several different models have been proposed (for an overview, see Jain and Dingh ${ }^{6}$ and Gupta et al. ${ }^{7}$ ). Customer lifetime value is most commonly defined as the sum of the discounted net cash flows generated by a customer during his/her relationship with the company. This definition can be expressed analytically by the following formula, based on standard methodology for the financial evaluation of assets: ${ }^{8}$

$$
C L V_{j}=\sum_{t=0}^{T} \frac{r_{j, t}-c_{j, t}}{(1+i)^{t}}
$$

where $j$ refers to the customer being evaluated, $r_{j, t}$ and $c_{j, t}$ are the revenue and cost generated by customer $j$ in time $t, i$ is the constant discount rate taking into account the time value of money, and $T$ is the duration of the relationship with the company. According to this formula for the computation of the lifetime value of a particular customer, we must forecast the revenues and costs at each future time step and estimate the remaining time interval (ie the lifetime) during which the customer generates revenues for the company.

Too often, however, because of data availability and complexity constraints, models only predict the average customer lifetime value at an aggregate level for the whole customer base ${ }^{9}$ without taking into consideration characteristics of the single customer. This limitation is a serious drawback, since profitability is usually not 
distributed uniformly among customers ${ }^{10}$ and a primary objective of the lifetime value approach is to identify highly profitable customers in order to keep existing ones and attract others. ${ }^{11}$ Equally, some customers may be nonprofitable for the company because the costs to serve them are too high or because they cannot be reached by marketing actions, leading to a negative return on investment. Obviously, investments in these customers should be avoided.

In contrast, more refined lifetime value models deal with individual customer values, as exemplified by Hansotia and Wang's ${ }^{12}$ right-censored tobit model, Reinartz and Kumar's ${ }^{13}$ negative binomial distribution (NBD/Pareto) model, and Drew et al. ${ }^{14}$ use of artificial neural networks (ANN) to predict an individual survival function based on customer input variables. Similarly, the lifetime value of each customer is predicted by Rust et al. ${ }^{15}$ using multinomial logistic regression, by Donkers et al. ${ }^{16}$ using a multivariate probit model, and by Tirenni ${ }^{17}$ using gaussian mixtures. Additional studies that address the durational aspect of individual customer lifetime value include recent work by Van den Poel and Larivière ${ }^{18}$ and Buckinx and Van den Poel, ${ }^{19}$ the aspect of risk involved in customer lifetime value and subsequent risk-sensitive allocation of marketing investments is addressed by Tirenni et al. ${ }^{20}$

Once individual customer lifetime value is known, it can be used to identify features linked to it. Therefore, in the following section, we define our own approach for segmenting customers according to lifetime value and finding factors that predict this value from known customer characteristics.

\section{DECISION TREES}

\section{Introduction}

To date, two extreme possibilities have existed for modelling customer lifetime value. The first, the above-mentioned evaluation of an average customer lifetime value, is unsuitable for value-based customer segmentation. Conversely, the second (and arguably best) method - that of predicting the exact numeric lifetime value at an individual level - is unnecessary for practical marketing applications, which only require that customers be classified into segments that can be treated with the same marketing instruments. Our approach follows a middle course in that we identify segments of customers according to their lifetime value (an aggregate segment approach) but predict the membership of a customer in one of these segments based on known individual features such as sales in the last three months or average transaction size (an individual feature approach).

The method we use for our customer value prediction are decision trees that have only scarcely been used in the customer value prediction literature. Nonetheless, decision trees ${ }^{21}$ are widely used in a broad spectrum of other fields to predict future classes given some input features. For example, application domains are employed in medical diagnosis, and response rate prediction in direct marketing ${ }^{22}$ and quality control. ${ }^{23} \mathrm{~A}$ recent study by Buckinx and Van den Poel ${ }^{19}$ uses decision trees (specifically, random forests - an extension of the classic method) to classify customers of a large retailer according to their likelihood of (partial) defection.

We consider decision trees an appropriate method for our study because they can potentially provide more valuable business insights than other classification methods (eg neural networks, logistic regression) by generating rules that clearly identify value drivers and the ways they influence lifetime value. Moreover, the fast computability of decision trees, especially compared to neural networks, makes them good candidates in a database marketing scenario in which thousands of customers must be processed and scalability of classification algorithms is very important.

Further advantages of decision trees are related to their high flexibility, which is 
especially useful if uncertainty exists a priori about the specific theoretical model.

Specifically, these advantages derive from five properties. First, decision trees are a

nonparametric method - meaning no

distributions (eg normality) or functional forms

(eg linearity) need be specified. In addition,

they are invariant to monotonic predictor

transformations (eg no logarithmic

transformations are required). Secondly, decision

trees require no preselection of variables; rather, a

robust stepwise selection process is used. Thus,

variables with a high explanatory power can

easily be separated from the remaining, less

important variables. Thirdly, regression trees

easily handle both continuous and categorical

variables and (automatically) include interactions

between variables, because cases are partitioned

and each group is analysed separately, meaning

that context dependency is considered.

Fourthly, decision trees are robust to the effects

of outliers, and finally, even if data cannot

generally be fitted well, decision trees can still generate useful results. This latter means that when the average performance of the output classification rules is poor, single rules can still perform extremely well and can greatly assist decision makers in improving the precision of their forecasts. This quality is especially useful for prospective customers about whom information is likely to be limited. In contrast, when other methods are used, the entire model is often discarded, meaning that, at minimum, fundamentally reliable information for some sub-segments is lost.

\section{The model}

Given a set of examples of the form $\{\langle X, Y\rangle\}$, where $X$ is an $n$-dimensional vector $X=\left[x_{1}, x_{2}, L, x_{n}\right]$ and $Y$ a categorical variable assuming a finite set of values (classes), a classification algorithm allows discovery of a function $h(x)$, mapping the vector $X$ to a class in $Y$ :

$$
h(x): X \rightarrow Y
$$

The $n$ components of the vector $X$ are the features (explanatory variables), while the variable $Y$ is the class (dependent variable). The sample $\{\langle X, Y\rangle\}$ is termed a training set. Once the function $h(x)$ has been learned from the training set, it can be applied to predict the class value associated with a given vector of features in other samples (test sets). Whereas the features $x_{i}$ can be continuous or discrete variables, the class $Y$ must be discrete (continuous variables may be discretised prior to decision tree use). For example, in a marketing context, the features might be demographic customer data like age, gender, city, income level, or family size, while the class might be the purchasing decision (yes or no) in answer to a marketing campaign. Using these data, a classification algorithm can not only generate rules that assign to each customer the expected answer to the next marketing campaign but can also produce a customer response probability for each of the possible answers.

As regards the optimisation algorithm, decision trees split the training set into partitions of sub-sets to improve the overall purity. Purity measures the degree to which objects with similar values of $X$ can be grouped into the same classes (values of $Y$ ). Technically, different criteria exist to measure the purity, including the Gini criterion, the information gain, and the information gain ratio criterion. ${ }^{24}$

To determine the splittings that maximise purity, all possible splitting points for all possible features are evaluated. For instance, numeric features have splits of the type $x_{i}<C_{n}$ for every value $C_{n}$ that the feature $x_{i}$ takes in the learning set. In the case of categorical features, the splits are of the form $x_{i}=C_{n}$. In every node, the split producing the best improvement in purity is selected. This process is repeated for each node until no significant improvement in purity can be achieved or until too few objects remain in the node. Terminal nodes are termed leaves and are labelled with the class to which the majority of examples in the leaf belong. 
As a result of the splitting algorithm, we obtain the classification function $h(x)$ in the form of a tree structure. This function allows classification of an object by checking its features at each node and following the branches until a leaf is reached. Each leaf is associated with a class value, which is the majority class of the examples belonging to the leaf. Figure 1 shows a simple hypothetical decision tree that predicts whether a prospect is or is not a potential customer based on gender and age.

It should be noted here that, when data not used in the learning phase are applied (ie using a test set), complex decision trees with very good performance on the training set can result in low performing trees because noise in the training set causes the model to overfit the training data. Therefore, if it will lead to an improvement in predictive performance (ie reduce misclassification error for unseen data), a procedure called pruning is used to replace some sub-trees with leaves. Pruning proceeds from the leaves backwards up towards the root. Different criteria developed to allow performance assessment and subtree replacement with leaves include crossvalidation and pessimistic pruning. ${ }^{21}$

In our specific case, we begin by using the value they previously generated for the firm to segment customers into three value segments (A, B and C), each defined by an

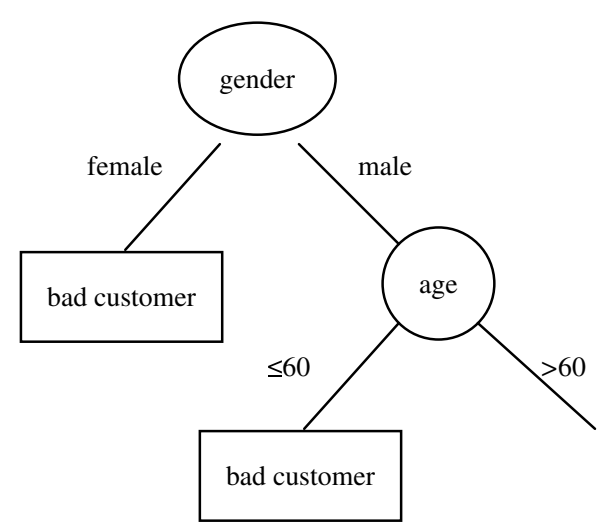

Figure 1: Hypothetical decision tree inferior and superior value boundary. For each customer $i$ in the training set, we now have a tuple: $c_{i, t}=\left\langle S_{i, t}, V_{i, t}\right\rangle$, where $S_{i, t}=\left\langle D_{i, t}, B_{i, t}\right\rangle$ - the state of this customer at time $t$ composed of demographic $\left(D_{i, t}\right)$ and behavioural features $\left(B_{i, t}\right)-$ and $V_{i, t}$ is the value segment of this customer. Using this information, we proceed by estimating decision trees to determine both the features that most characterise a given segment and the prediction rules that link the customer features to associated class values (ie segment types). The rules generated from the training sample allow prediction of the value segment of new customers (and of incumbent customers from other samples) based on their known characteristics.

\section{A CASE STUDY}

\section{Data}

We illustrate our approach using data for a major European airline covering January 2000 to December 2002. The data have been exported from the airline's database to several text files using the export functionalities of the database system. Moreover, a description of the data schemas (ie attributes, primary keys, and data types) has been provided by the airline company so that we could rebuild a local database to compute all required features. We created a relational database in which all data stored in the text files have been imported. Using SQL scripts, we removed all inconsistent data (eg outliers, corrupted data, missing values) and obtained the transaction history and demographic information of about 450,000 customers. This database has been randomly split into two sub-samples: a learning sample of 60 per cent of the observations (approximately 270,000 customers) and a test sample of 40 per cent of the observations (approximately 180,000 customers). Tables 1 and 2 describe the available demographic data and customer behavioural features (ie those related to customer buying behaviour), which have 
Table 1: Demographic features as of December 2001

\begin{tabular}{lll}
\hline Variable name & Explanation & Scaling \\
\hline Gender & Male or female & Categorical \\
Age & Customer age & Numeric \\
Language & Language for communicating with the company & Categorical \\
Nation & Nation of residence (Nationlists 1-3) & Categorical \\
Region & Region of residence & Categorical \\
City & City of residence & Categorical \\
Family number & Number of people in the customer's family & Categorical \\
Post indicator & Takes the value 1 if the given address for mail correspondence is the & Categorical \\
& working or home address, and 0 otherwise & \\
Seat preference & Window, aisle & Categorical \\
Meal preference & Type of meal & Categorical \\
Hobbies & Customer hobbies (eg, golf, opera.) & Categorical \\
Email offers & Takes the value 1 if the customer wishes to receive special offers by & Categorical \\
SMS offers & email, and 0 otherwise. & \\
& Takes the value 1 if the customer wishes to receive special offers by & Categorical \\
\hline
\end{tabular}

Table 2: Behavioural features

\begin{tabular}{|c|c|c|}
\hline Variable name & Explanation & Scaling \\
\hline Value new (dep. variable) & Sales generated from January 2002 to December 2002 & Numeric \\
\hline Value & Sales generated in January 2002 & Numeric \\
\hline Value 3 & Sales generated from October 2001 to December 2001 & Numeric \\
\hline Value 6 & Sales generated from July 2001 to December 2001 & Numeric \\
\hline Value 12 & Sales generated from January 2001 to December 2001 & Numeric \\
\hline Frequency & Number of trips in January 2002 & Numeric \\
\hline Frequency 3 & Number of trips from October 2001 to December 2001 & Numeric \\
\hline Frequency 6 & Number of trips from July 2001 to December 2001 & Numeric \\
\hline Frequency 12 & Number of trips from January 2001 to December 2001 & Numeric \\
\hline Average transaction size & Average amount of money spent in each transaction. & Numeric \\
\hline Average transaction size 3 & $\begin{array}{l}\text { Average amount of money spent in one transaction between } \\
\text { October } 2001 \text { and December } 2001\end{array}$ & Numeric \\
\hline Average transaction size 6 & $\begin{array}{l}\text { Average amount of money spent in one transaction between } \\
\text { July } 2001 \text { and December } 2001\end{array}$ & Numeric \\
\hline Average transaction size 12 & $\begin{array}{l}\text { Average amount of money spent in one transaction between } \\
\text { January } 2001 \text { and December } 2001\end{array}$ & Numeric \\
\hline Miles & Number of miles flown in January 2002 & Numeric \\
\hline Miles 3 & $\begin{array}{l}\text { Number of miles flown between October } 2001 \text { and } \\
\text { December } 2001\end{array}$ & Numeric \\
\hline Miles 6 & $\begin{array}{l}\text { Number of miles flown between July } 2001 \text { and December } \\
2001\end{array}$ & Numeric \\
\hline Miles 12 & $\begin{array}{l}\text { Number of miles flown between January } 2001 \text { and December } \\
2001\end{array}$ & Numeric \\
\hline Longevity & Number of days since first transaction & Numeric \\
\hline Recency & Number of days since last transaction & Numeric \\
\hline Join days & Number of days since joining & Numeric \\
\hline
\end{tabular}

been computed using appropriate SQL scripts, respectively. Demographic data refer to December 2001; the dates in which behavioural features have been computed are described in Table 2.

All behavioural features refer to a predefined time interval and have been computed from the transactional data, which contain all the information related to the transactions executed by the customers over time (eg revenue, type of flight, answers to a marketing campaign). Since our data include only information about revenues not costs, we focus our analysis on revenues not profits. The degree to which results using revenues or profits differ 
obviously depends on the disparity of costs per customer. If costs are identical, then (relative) customer value segments do not change when costs are omitted from the value calculation. Regardless, prediction of customer revenues instead of profits is useful in its own right as information that allows optimisation of marketing costs spent on each customer and thus profitability maximisation. Thus, in the remainder of this paper, despite not addressing costs, we will use the term customer value.

The value generated by a customer between January and December 2002 ('value new') is used as the dependent variable, while all values generated before this time are regarded as independent variables.

\section{Value-based segmentation}

Because our data suggest that customer lifetime value is best defined as the customer value for a given period, we choose the sum of all revenues generated by a given customer in one year:

$$
C L V_{i}=\sum_{t=1}^{365} r_{i, t^{\prime}}
$$

where $\mathrm{CLV}_{i}$ is the lifetime value of customer $i, t$ is the time unit in days, and $r_{i, t}$ is the revenue generated by customer $i$ at time unit $t$. In this lifetime value definition, we neither discount cash flows nor (as indicated above) consider costs.

We compute a defined lifetime value for all customers that made at least one transaction in the years 2000, 2001, and 2002. After ranking all the customers according to their lifetime value, we obtain inverted Lorenz curves, exemplified in Figure 2 by the case of 2002 .

In this figure, the horizontal axis represents the cumulative percentage of customers ordered from the most to the least profitable. The vertical axis represents the percentage of cumulative value generated by the corresponding share of

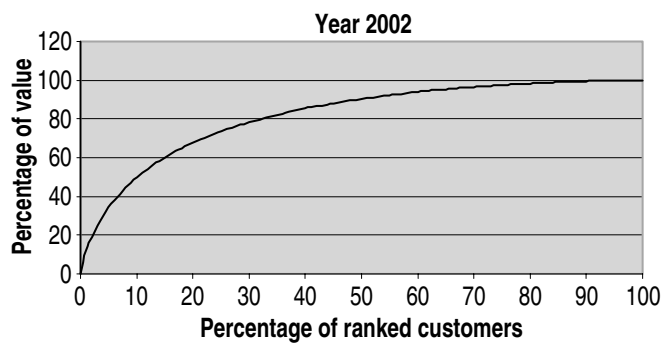

Figure 2: Lifetime value of all customers in 2002

customers. As the curve shows, the top 10 per cent of the customers generate almost 50 per cent of, and the first 30 per cent generate almost 80 per cent of, the total value (the exact values for each decile and corresponding segment are presented in Table A1 in the Appendix).

We use these findings to derive the value-based segmentation as displayed in Table 3.

The last column shows the value lift, the average lifetime value of a segment divided by the average lifetime value of the whole customer base:

$$
\operatorname{lift}_{\mathrm{s}}=\frac{\overline{C L V_{S}}}{\overline{C L V}}=\frac{\text { \%value }_{S}}{\% \text { size }_{S}},
$$

where $S$ refers to the segment (A, B, or C).

As the figures in Table 3 clearly show, the customer value generated varies greatly across segments and declines strongly from segment $A$ to segment $C$. For instance, the segment A lift factor shows the average lifetime value of segment A to be almost five times higher than the average lifetime value of the whole population; in contrast, the average lifetime value of segment $\mathrm{C}$ customers is less than a third of the average.

\section{Prediction of the value segment}

The next step is to link the available customer information to membership in one of the above-defined segments. The first information we apply is the duration of the customer's previous relationship with the 
Table 3: Segmentation of customers

\begin{tabular}{llll}
\hline Segment & $\begin{array}{l}\text { Percentage of } \\
\text { Customers }\end{array}$ & $\begin{array}{l}\text { Approx. } \\
\text { value } \\
\text { generated } \\
\text { (\%) }\end{array}$ & $\begin{array}{l}\text { Value } \\
\text { lift }\end{array}$ \\
\hline A & $\begin{array}{l}\text { Top 10\% of } \\
\text { customers } \\
\text { Next 20\% of } \\
\text { customers }\end{array}$ & 50 & 4.96 \\
C & $\begin{array}{l}\text { Remaining 70\% } \\
\text { of customers }\end{array}$ & 20 & 1.43 \\
\hline
\end{tabular}

company. Since this information decides the availability of other behavioural information, as well as the time span to which such information refers, we use information about the relationship duration to (pre-) divide our customer base into three subsamples for which separate models are estimated. According to the customer's relationship duration we identify:

- Long-term customers: These persons have been customers of the company for at least 12 months; therefore, the behavioural features of the last 12 months are known.

- Middle-term customers: Only the behaviour during the last three months is known.

- New customers: Only the behaviour during one month is known.

- Prospects: No transactions are registered in the database; only demographic information is available. These customers registered their demographic information in the company database but have not yet purchased anything from the company.

For these four groups of customers we estimate separate decision trees, meaning we predict the value segment based on all known demographic and behavioural features. For confidentiality reasons, we rescale the values of all numerical features except age, frequency, and family number using a linear mapping. Moreover, we refer to groups of nations or regions with symbolic list names (eg Nationlist 1, Regionlist 1) without disclosing the exact names.

\section{RESULTS OF THE MODEL ESTIMATION \\ Long-term customers}

For long-term customers, we consider all features described in Table 2 and summarise the output of the decision tree by the following rules:

1 If value 12 is $>200$, then segment $A$.

2 If value 12 is between 140.3 and 200 , then segments $\mathrm{A}$ or $\mathrm{B}$.

3 If value 12 is between 110.7 and 140.3 and $>135$, then segment $A$.

4 If value 12 is between 110.7 and 140.3 and value is between 100.9 and 135 , then segments $\mathrm{A}$ or $\mathrm{B}$.

5 If value 12 is $<110.7$, gender is female, nation belongs to Nationlist 1 , and the post indicator is not 1 , then segment $\mathrm{C}$.

As is apparent, this list includes only some of the decision rules contained in the tree. We report only those rules that have a misclassification error rate of less than 15 per cent on the independent test sample. This criterion means that, for instance, at least 85 per cent of the customers following rule 1 are in segment $A$.

The above rules indicate that the features that best predict the value segment in the next year are the aggregate value in the last 12 months and the value in the current month. For high-value long-term customers, demographic information plays no relevant role. Rule 5 predicts customers who generate low values for the company. Specifically, these customers are females who belong to a list of nations not identified for confidentiality reasons. Moreover, in the case of these customers, the post indicator is not 1 , meaning they wish to receive mail at their home addresses not their office addresses (post indicator $=0$ ) or that they specified no preferred address (post indicator $=$ missing). Most probably, these low-value customers travel privately rather than for business purposes or, in 
some cases, may not even have an office address.

These findings can be summarised as follows. First, as might be expected, for long-term customers, previous spending is the predominant factor explaining customer value in the successive year, particularly for higher value customers. The group of customers for whom we can most clearly predict a low value for the company has the following features: they are females, from certain nations, tend to be nonbusiness travellers, and have spent little in the previous periods. These findings confirm our intuitive assumptions.

\section{Middle-term customers}

In the case of middle-term customers, only the transaction history of the last three months is known (ie October 2001 to December 2001). The resulting decision tree can be summarised by the following primary rules:

1 If value 3 is $>133$, then segment $A$.

2 If value 3 is between 116.4 and 133 and miles are $>118$, then segment $\mathrm{A}$.

3 If value 3 is $<107.8$, average transaction size is $>106$, and frequency is $>1$, then segment $\mathrm{A}$.

4 If value 3 is $<107.8$ and average transaction size $>98$, then segment A or B.

5 If value 3 is $<101.2$, gender is female, average transaction size is $<98$, post indicator is not 1 , and nation belongs to Nationlist 2, then segment C.

These rules have a misclassification error rate of less than 25 per cent, compared to 15 per cent for long-term customers. This greater error rate results from customers' behavioural features being known for only three months instead of 12 months, meaning less information is available. As in the case of long-term customers, the feature with the most predictive power is previous customer value. Again as a result of the lower observation time for this variable however, other information becomes more important than in the case of long-term customers. For instance, customers with a high number of miles tend to create higher value. The same applies for average transaction size and frequency. As regards the decisive variables, rule 5 , which identifies the lowest value customers, is similar to rule 5 for long-term customers. It is noteworthy, however, that - opposed to our results for long-term customers - it is Nationlist 2 that indicates a low value rather than Nationlist 1.

The rules generated for middle-term customers also reveal a special rule property generated by regression trees that is worth pointing out. Specifically, the prediction rules presented here are not always mutually exclusive. For instance, rule 3 is a special case of rule 4 , meaning that if rule 3 can be applied, then rule 4 can also be applied, but not vice versa because the node in the tree identified by rule 4 is a parent of the node representing rule 3 . Rule 3 defines a smaller set of cases with a higher prediction precision (observations are classified only into segment $\mathrm{A}$ rather than segment $\mathrm{A}$ or $B)$. Thus, describing the rules associated with all leaves of the tree would produce a set of mutually exclusive rules classifying each customer. Because of over-fitting, not all these rules would perform well for other than the training sample. To avoid this problem, we present only those rules that have a small prediction error in both the learning and test samples.

In sum, the most important predictor for future customer value is spending in the last three months. In addition, a low average transaction size (among other features) indicates low-value customers, as do female gender and customer wishes to receive mail at their home addresses.

\section{New customers}

In the case of new customers, only the behavioural features for one month are known (ie January 2002 in our data set), a 
lack of historical data that makes it more difficult to predict the customer's value during the whole year. The rules with the highest predictive power are as follows:

1 If value is $>110$, then segment $A$.

2 If value is between 101.2 and 110 , then segment $\mathrm{A}$ or $\mathrm{B}$.

3 If value is $<101.2$ and seat preference is specified, then segment $A$ or $B$.

4 If value is $<101.2$, seat preference is not specified, gender is female, and post indicator is not 1 , then segment $C$.

5 If value is $<101.2$, seat preference is not specified, gender is male, family number is not specified, post indicator is 0 , and age is $<28$, then segment $\mathrm{C}$.

Interestingly, the previous rules still have a misclassification error of less than 25 per cent in the test sample, which is the same value as for middle-term customers.

Once again, previous customer value is the most important feature for explaining future value. Given the small amount of information related to past customer behaviour, the demographic features become important; in particular, gender, age, seat preference, and office post indicator. As before, such information is especially relevant for low-value customers. One new finding is that a specification of seat preference points to a higher customer value, arguably indicating that customers with seat preferences are more experienced flyers and have clearer preferences. Another characteristic signalling a low customer value is gender. As with the previous results, being female and not wishing to receive mail at the office points to a low-value customer. The same, however, applies for young males who do not specify the number of family members and wish to receive mail at home. Possible explanations are that these young customers tend to travel for pleasure rather than business and, since family number is not specified, tend to be single. It is quite probable that these customers try to save money, search broadly for special flight offers, and, even more important, show little loyalty to a specific airline.

Based on these findings, we conclude that new customers are likely to generate a high value if they have previously spent a considerable amount of money and specify a seat preference. Otherwise, their value will be low, particularly if they wish to receive their mail at home, are young, and have not yet begun a family.

\section{Prospects}

Prospects are customers who joined the company by registering their demographic information in the database. The resulting unavailability of behavioural information makes the task of predicting the value segment very challenging. The main rules derived from the decision tree are as follows:

1 If seat preference is aisle, region is in Regionlist 1 , and family number is between 1 and 6 or not specified, then segment A.

2 If seat preference is window, region is in Regionlist 2, family number is between 1 and 6 or not specified, and gender is male, then segment $\mathrm{A}$ or $\mathrm{B}$.

3 If seat preference is not specified, gender is female, post indicator is 0 , and age is not between 26 and 55 , then segment C.

These rules have a misclassification error rate of less than 30 per cent. Compared to the previous cases, we clearly observe a degradation of predictive accuracy both in terms of the quality and quantity of the rules. In fact, the above three rules only apply to particular types of customers; most others remain excluded and are thus not classified at all (eg males not in Regionlist 1 or 2). The fact that at least some statistically reliable rules are, however, available for some types of customers can still help marketing managers choose marketing campaign targets. 
Given the lack of available information about previous customer value and transactions, seat preference becomes the feature with the highest predictive power for this group. In general, high-value customers (ie segments A and B) have a seat preference - specifically, the highest value customers are those who prefer to sit in the aisle. An intuitively appealing explanation is that business flyers have a clear seat preference for the aisle because they are less interested in looking at the landscape than being able to get up quickly.

As in the new customer case, low value customers are those who do not specify any seat preference and wish to receive their mail at home. They may again be under the age of 26 but could also be over 55 years, meaning that retired people travelling for private reasons are also included in this low-value group.

On the whole, our findings for this group suggest that reason for travelling, whether for business or private reasons, is an important indicator of prospective customer value. Seat preference appears to act as the most important proxy for this information, but it would be preferable to know the explicit customer type. Therefore, we asked the company to provide us corporate data about new customers registered in the database, thereby allowing us to classify them into the following two categories:

- Corporate customers. If there is an agreement between the airline company and the customer's employer, then customers are classified as corporate customers. Corporate customers often (but not always) fly at the employer's expense.

- Noncorporate customers. This category includes all other customers. Here, the customer's employer has no official agreement with the airline company; however, the customer might still fly for business reasons and have the costs covered by the employer. Nonetheless, on average, these customers are more likely than corporate customers to fly for private reasons.

Knowing whether a prospect is a corporate customer or not improves the predictive accuracy of the decision tree, leading to generation of the following prediction rules:

1 If a customer is corporate and seat preference is specified, then segment A.

2 If a customer is corporate and seat preference is not specified, then segment A or B.

3 If a customer is not corporate, seat preference is not specified, gender is male, family number is not specified, post indicator is 0 , and age is $<30$, then segment C.

4 If a customer is not corporate, seat preference is not specified, gender is female, and post indicator is 0 , then segment C.

These rules again have a minimum misclassification error rate of 25 per cent (the same as for middle-term and new customers). More specifically, rule 1 has an error rate of only 10 per cent, which is very low compared to the rule 1 error rate of 20 per cent when no corporate information is available. This example demonstrates how a new feature can improve the predictive performance of a decision tree. Indeed, the corporate or noncorporate customer designation becomes the most important feature for customer value. Nonetheless, it does not entirely replace seat specification. Rather, seat preference appears to have some function beyond that of simply separating business and private travellers, possibly that travellers who specify seat preference are more experienced and/or travel more frequently. Hence, corporate customers are generally the most valuable, but among them, those who are more experienced (and have a seat preference) are the best. According to rules 
3 and 4, comparatively bad customers are unexceptionally noncorporate flyers who specify no seat preference. Among these, two groups again emerge: young males (as in previous rules) and, more generally, females with a private mail address. Finally, we note that neither country nor region plays any role in these last classification rules.

In all, the information already entered for prospects gives good indication of their future value. Particularly valuable are whether a prospect is a corporate customer and specifies a seat preference, and, in the latter case, which seat is preferred. The best customers appear to be corporate customers that choose an aisle seat, while low-value customers tend to be young people who have not yet started a family and prefer to receive mail at their home addresses.

\section{MANAGERIAL IMPLICATIONS}

The prediction rules described in the previous section can be used to manage customer relations by enabling customer relations managers to allocate marketing resources based on the predicted profitability levels. Because the departure of high-valued customers, as opposed to that of low-valued customers, significantly reduces long-term economic performance, marketing initiatives should primarily be aimed at retaining the few (relative to the whole customer base) high-value customers and acquiring new ones.

The first step of our analysis clearly illustrates substantial differences in customer value. The top 10 per cent of customers in the European airline data set generate almost 50 per cent of the value, while 30 per cent of the customers (ie segments A and $\mathrm{B}$ ) are responsible for almost 80 per cent of the annual revenues. This result indicates that $\mathrm{A}$ customers are on average 3.5 times more profitable than B customers. Therefore, improving the retention rate of $\mathrm{A}$ customers would have a strong leveraging effect on improvement of the whole customer equity.

Before (future) high-valued customers can be targeted by appropriate loyalty campaigns, they must be identified, a problem for which we provide a solution in our second analytical step. Identifying the future value of customers based on the demographic data on their previous behavioural features enables their efficient allocation on a (limited) marketing budget to different customer segments. Evidently, as segment A contains the most valuable customers, it is efficient to spend the highest per head amount on customers who are likely to belong to this segment. For instance, the predictive rules for long-term customers indicate that these customers generated a value of more than 200 in the last 12 months. In contrast, lowvalue customers (segment $C$ ) should not receive too much attention.

Another, more coarsely grained strategy for resource allocation could be oriented solely to demographic features. For example, once regions and countries with high-value customers have been identified, marketing resources might be allocated on a national and regional basis. More generally, all features appearing in a decision tree can be exploited to allocate marketing investments. Moreover, decision trees can be used to detect changes in customer consumption patterns by comparing the predicted future value segment with the observed historical segment. Basically, two types of change can be predicted:

- If the observed historical value segment is higher than the predicted future value segment, the customer is tending to downgrade.

- If the observed historical value segment is lower than the predicted future value segment, the customer is tending to upgrade.

Based on perceived changes in the value segment, customer relations managers can then design different marketing strategies. 
For example, customers predicted to upgrade could be addressed by loyalty campaigns aimed at minimising their defection rate. Customers predicted to downgrade, especially those likely to downgrade from segment A to B, could be targeted with campaigns aimed at giving them incentives to increase, or at least maintain, their service consumption rate. Another solution would be to target these same customers with cross-selling campaigns designed to increment their lifetime value and thus avoid downgrading.

\section{References}

1 Woo, K. and Fock, H. K. (2004) 'Retaining and divesting customers: An exploratory study of right customers, "at-risk" right customers, and wrong customers', Journal of Services Marketing, Vol. 18, pp. 187-197.

2 Anderson, E. W. and Mittal, V. (2000) 'Strengthening the satisfaction-profit chain', Journal of Service Research, Vol. 3, pp. 107-120.

3 Niraj, R., Gupta, M. and Narasimhan, C. (2001) 'Customer profitability in a supply chain', Journal of Marketing, Vol. 65, pp. 1-16.

4 Reinartz, W. J. and Kumar, V. (2002) 'The mismanagement of customer loyalty', Harvard Business Review, Vol. 80, pp. 86-94.

5 Ryals, L. (2003) 'Creating profitable customers through the magic of data mining', Journal of Targeting, Measurement and Analysis for Marketing, Vol. 11, pp. 343-349.

6 Jain, D. and Singh, S. S. (2002) 'Customer lifetime value research in marketing: A review and future directions', Journal of Interactive Marketing, Vol. 16, pp. 34-46.

7 Gupta, S., Lehmann, D. R. and Stuart, J. A. (2004) 'Valuing customers', Journal of Marketing Research, Vol. 41, pp. 7-18.

8 Brealey, R. and Myers, S. (1996) 'Principles of corporate finance', McGraw-Hill, New York.

9 Rust, R., Zeithaml, V. and Lemon, K. (2000) 'Driving customer equity: How customer lifetime value is reshaping corporate strategy', Free Press, New York.

10 Mulhern, F. J. (1999) 'Customer profitability analysis: Measurement, concentration, and research directions', Journal of Interactive Marketing, Vol. 13, pp. 25-40.

11 Bayón, T., Gutsche, J. and Bauer, H. (2002) 'Customer equity marketing: Touching the intangible', European Management Journal, Vol. 20, pp. 213-222.

12 Hansotia, B. and Wang, P. (1997) 'Analytical challenges in customer acquisition', Journal of Direct Marketing, Vol. 11, pp. 7-19.

13 Reinartz, W. J. and Kumar, V. (2000) 'On the profitability of long-life customers in a noncontractual setting: An empirical investigation and implications for marketing', Journal of Marketing, Vol. 64, pp. 17-35.

14 Drew, J., Mani, D. R., Betz, A. and Datta, P. (2001) 'Targeting customers with statistical and data-mining techniques', Journal of Services Research,Vol. 3, pp. 205-219.

15 Rust, R., Lemon, K. and Zeithalm, V. (2004) 'Return on marketing: Using customer equity to focus marketing strategy', Journal of Marketing, Vol. 68, pp. 109-127.

16 Donkers, B., Verhoef, P. C. and de Jong, M. (2003) 'Predicting customer lifetime value in multi-service industriesWorking Paper, School of Management, Erasmus University, Rotterdam.

17 Tirenni, G. (2005) 'Allocation of marketing resources to optimize customer equity', $\mathrm{PhD}$ Thesis, University of St. Gallen, Switzerland. Available at: www.unisg.ch/edis.

18 Van den Poel, D. and Larivière, B. (2004) 'Customer attrition analysis for financial services using proportional hazard models', European Journal of Operational Research, Vol. 157, pp. 196-217.

19 Buckinx, W. and Van den Poel, D. (2005) 'Customer base analysis: Partial defection of behaviourally loyal clients in a non-contractual FMCG setting', European Journal of Operational Research, Vol. 164, pp. 252-268.

20 Tirenni, G., Labbi, A., Berrospi, C., Elisseeff, A., Heinonen, K., Pauro, K. and Korppi, T. (2007) 'Customer Equity and Lifetime Management (CELM) Finnair case study', Marketing Science, forthcoming.

21 Quinlan, J. R. (1996) 'Improved use of continuous attributes in C4.5', Journal of Artificial Intelligence Research, Vol. 4, pp. 77-90.

22 Haughton, D. and Oulabi, S. (1997) 'Direct marketing modeling with CART and CHAID', Journal of Direct Marketing, Vol. 11, pp. 42-52.

23 Müller, W. and Wiederhold, E. (2002) 'Applying decision tree methodology for rules extraction under cognitive constraints', European Journal of Operational Research, Vol. 136, pp. 282-289.

24 Quinlan, J. R. (1993) 'C4.5: Programs for machine learning', Morgan, San Mateo, CA.

\section{Appendix}

Table A1: Total customer value of different segments

\begin{tabular}{lcl}
\hline $\begin{array}{l}\text { Percentage } \\
\text { customers }\end{array}$ & Percentage value & Segment \\
\hline 0 & 0 & $\mathrm{~A}$ \\
10 & 49.6246 & $\mathrm{~A}$ \\
20 & 67.6024 & $\mathrm{~B}$ \\
30 & 78.2604 & $\mathrm{~B}$ \\
40 & 85.345 & $\mathrm{C}$ \\
50 & 90.3309 & $\mathrm{C}$ \\
60 & 93.9123 & $\mathrm{C}$ \\
70 & 96.4618 & $\mathrm{C}$ \\
80 & 98.2685 & $\mathrm{C}$ \\
90 & 99.4606 & $\mathrm{C}$ \\
100 & 100 & $\mathrm{C}$ \\
\hline
\end{tabular}

